\title{
The Temperature and Relative Humidity Change in Wheat Bulk under the Condition of Temperature Differences
}

\author{
Jun Yin ${ }^{1}$, Zhongjie Zhang ${ }^{1}$, Xiaomeng Wang ${ }^{1,2}$, Qu Yao ${ }^{1}$, Zidan $\mathbf{W u}^{2}$ \\ ${ }^{1}$ Academy of State Administration of Grain \\ No. 11 Baiwanzhuang Street, Xicheng District, Beijing 100037, China \\ E-mail:yjun@chinagrain.org \\ ${ }^{2}$ Biological and Agricultural Engineering School, Jilin University \\ No. 5988 Renmin Street, Nanguan District, Changchun City, Jilin Province 130025, China \\ wuzidan@263.net
}

\begin{abstract}
In stored-grain bulk, its state would be affected by the coupling actions of temperature, humidity, moisture, gas and so on. However the most important factors are temperature and humidity. In the paper, the wheat was sealed in the $30{ }^{\circ} \mathrm{C}$ temperature difference simulation bin for about $75 \mathrm{~d}$. The results indicated that the fastest of the temperature change rate was the upper of grain bulk in the same vertical direction of the same plane. In the same way, the grain with nearer to the high temperature district was faster temperature rise and higher amplitude. To the relative humidity of grain bulk, the change of the close to higher temperature grain zone was fiercer than the others. And the relative humidity of low temperature area would change gently. The micro-airflow in grain mainly stemmed from the temperature differences. So the migration and redistribution of the temperature and relative humidity in wheat bulk was caused by the actions of conduction and convection. And the convection was the predominant action in grain bulk. In addition, the differences between heat and mass transfer in vertical and horizontal direction could demonstrate that the grain is anisotropy.
\end{abstract}

Keywords: temperature, relative humidity, micro-airflow, anisotropy

\section{Introduction}

China is the world's largest grain producer and consumer. And its grain reserves have the following features: longterm storage, different storage-ecological districts, large grain bulk, diversified grain species. Therefore it can be concluded that it's a great challenge to ensure the safety of grain storage[1]. At first, which factors could impact on the stored-grain safety. It is well known that they are temperature, humidity, moisture, gas and so on. Moreover two vital factors of effecting storage state are temperature and relative humidity[2,3]. Otherwise, if the temperature and relativity humidity were higher and higher, the grain safety would be destroyed. The mould or grain-insects probably occured. In addition, the adsorption, desorption and respiration of grain itself, the grain quality would deteriorate[4,5].

Secondly, the micro-airflow is attributed to temperature difference and humidity difference in grain bulk. Then it resulted in migration and redistribution of temperature and humidity[6,7]. If the change regulation of temperature and humidity was obtained, the state of grain storage would be predict. Therefore in the paper, the wheat, which was located in the certain temperature difference closed bin, was researched. The resulted demonstrated that the change of temperature and humidity mainly stemmed from micro-airflow moving. It can provide theoretical basis for predicting grain-storage state. 


\section{Materials and Methods}

\subsection{Materials}

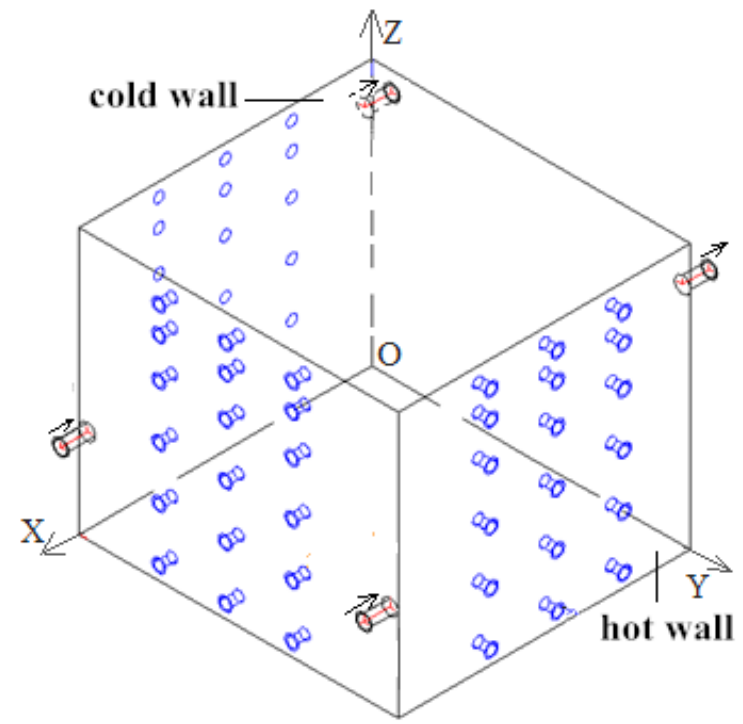

Fig. 1: The bin of stored wheat schematic diagram.

The inside size of bin (Fig.1) is length $\times$ width $\times$ height=1.0 $\mathrm{m} \times 1.0 \mathrm{~m} \times 1.0 \mathrm{~m}$. The $\mathrm{XOZ}$ plane is cold wall $\left(15^{\circ} \mathrm{C}\right.$ wall), and the opposite's is hot wall $\left(45^{\circ} \mathrm{C}\right.$ wall). The others are adiabatic insulation. The bin was placed in $20^{\circ} \mathrm{C}$ atmosphere of the room. Two upper holes of YOZ plane are air-outlet, the opposite's are air-inlet.

The wheat was collected from a local farm in Hebei Province of China. Its initial temperature and moisture content were $20^{\circ} \mathrm{C}$ and $14.4 \%$ w.b., respectively. It was placed in the bin without any pressure. The sensors were collocated in different length of $X$ direction, such as $X=100 \mathrm{~mm} 、 350 \mathrm{~mm} 、 500 \mathrm{~mm} 、 850 \mathrm{~mm}$. The sensors of each parallel ZOY plane were distributed uniformly (Fig. 2).

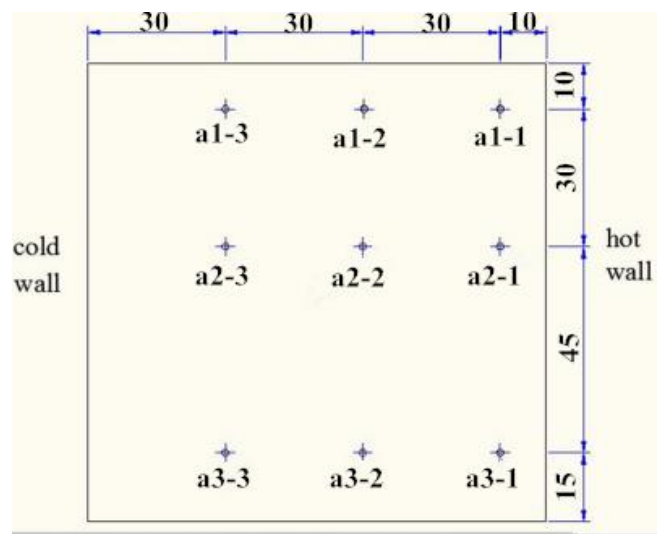

Fig. 2: The sensors of each parallel $Z O Y$ plane schematic diagram.

\subsection{Methods}

The data was recorded every 2 hours, which included wheat temperature, wall temperature, porous air relative humidity. Then $X=500 \mathrm{~mm}$, parallel $Z O Y$ plane was studied and it was called as the mid-plane. The change regulation of wheat bulk with researched plane reflected itself characters regardless of environmental influence.

\section{Results and Discussion}

The temperature change was showed in Fig.3. The nearer to hot district was the faster temperature rise rate. But in the same vertical lines, the most sharply temperature change was wheat bulk surface, the gentlest ones was the below 
of wheat bulk. In other words, the rate of the upper wheat temperature was larger than the others, and the value of its temperature rise was higher. However the change tendency was the same in the same vertical direction.

It is well known that the temperature change is caused by conduction, convection and radiation. In the experiment, the wheat temperature and test bin's were no less than $45^{\circ} \mathrm{C}$. Therefore the radiation was very weaker and weaker. Then the action of conduction and convection led to the temperature change. Firstly, if the grain conduction was isotropy, the temperature of the wheat bulk would be all the same. Yet, the results were different from the hypothesis conclusion. Thus grain conduction was anisotropy. In addition, grain conduction was very slow. In short time, the temperature change was very obvious. It was conclude that the convection was widely contributed to temperature change. In the test, the bin was full of the wheat. And the grain belongs to the porous material. So the source of convection was the air in wheat bulk.

The convection action had performed as micro-airflow moving. If the wheat temperature was all the same, the microairflow would be static. In fact, the wheat temperature was different. Then the micro-airflow density was smaller with the temperature rising. Then it moved upwards. Therefore the change rate of the top was faster than the others.

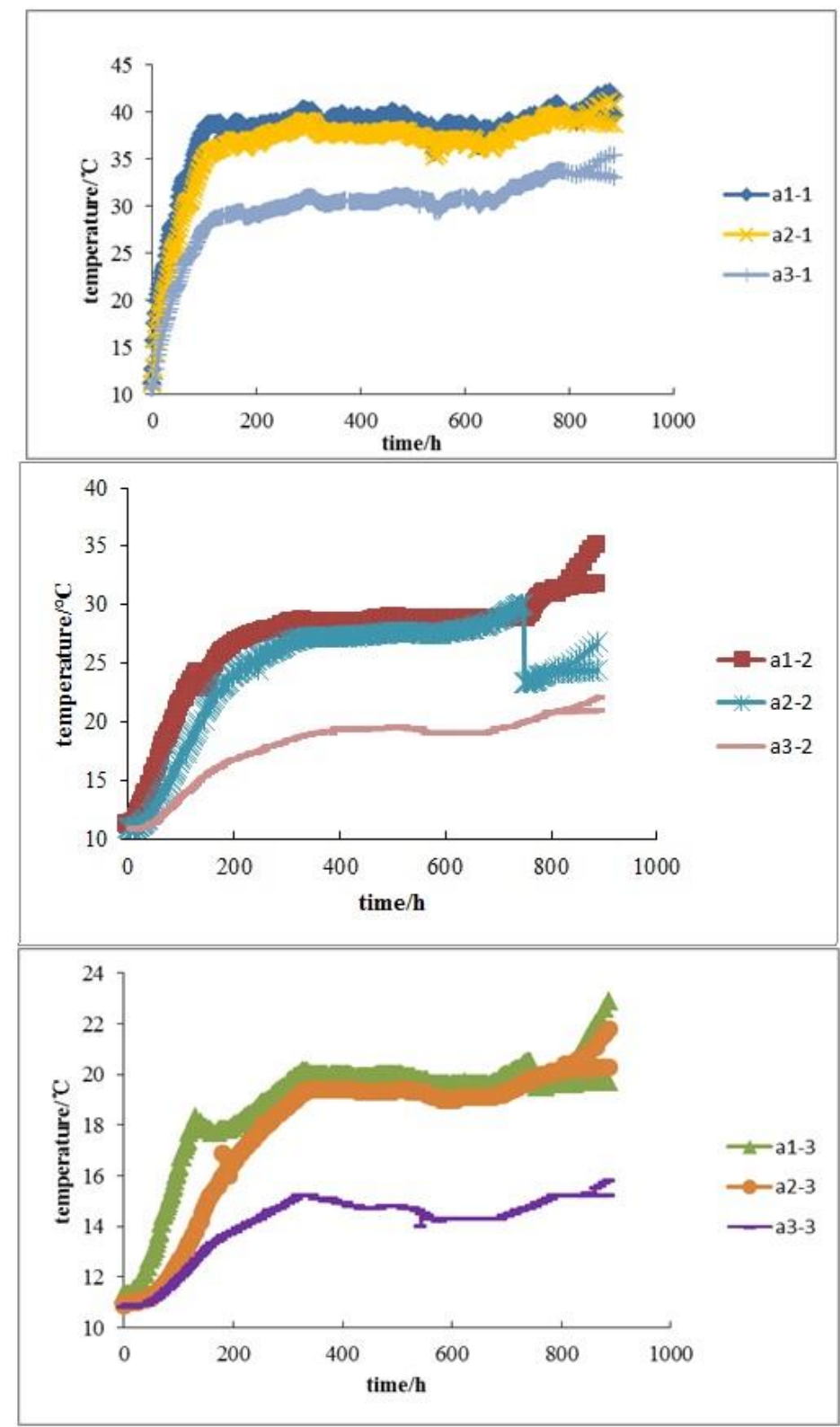

Fig. 3: The temperature change with the same vertical lines in the mid-plane. 
The relative humidity change regulation was presented in Fig.4. The change tendency was the same as the temperature's. Firstly, the $0.1 \mathrm{~m}$ distance between hot wall and the vertical line in the mid-plane, the relative humidity was increasing then descending because of the micro-airflow. The moving direction of micro-airflow was the below of the hot wall then the vertical upwards. When the upward moving, the relative humidity was higher then drastically decreased with the temperature rising. At that time, the wheat adsorption was stronger than desoprtion, but the temperature further increasing, the desorption would be dominant.

The areas of the middle and closed the cold wall were basically slowly rising relative humidity. And the amplifier was the most in the upper wheat. Moreover the below wheat was the less amplifier. Besides the micro-airflow density of the low temperature could be bigger and bigger, it moved downwards. It was inferred that its moving direction was the below of the hotter area-the vertical upwards-the horizontal to the colder zone-the vertical downwards-the horizontal to the hot ones.

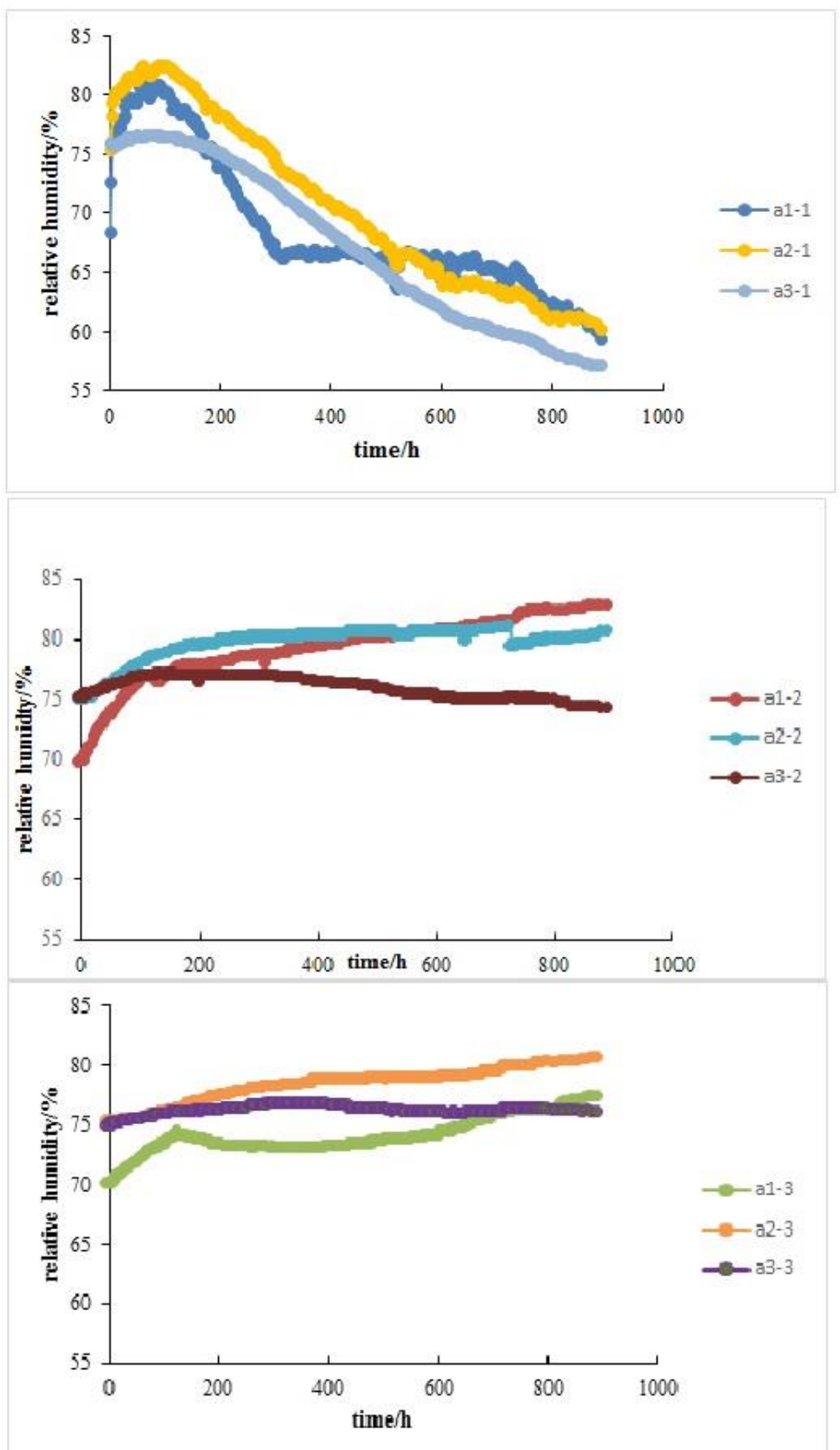

Fig. 4: The relative humidity change with the same vertical lines in the mid-plane. 
In Fig. 3 and 4, the temperature change was faster than the relative humidity's. The relative humidity change of the heat district was first increased then decreased with the temperature raise and gentle. Thus the wheat of the part can be safe. However the relative humidity of the middle part was slowly lifting, the much moisture was migrating to the cold ones with the moving direction and strength of micro-airflow. But a large number of the moisture and humidity came to the cold zone. The wheat adsorption was limited because of the low temperature. After a few times, the cold wheat would be saturated. If the relative humidity went on raising, the condensation would be appeared, meanwhile the earliest location maybe the cold wheat surface.

\section{Conclusion}

The temperature difference action was resulted in the micro-airflow. At the same time, the coupling actions of the conduction and convection, the migration and redistribution of temperature and moisture happened. Besides, the grain is anisotropy porous material. The change of the temperature was faster than the relative humidity. It was concluded that the moving direction of micro-airflow was a closed-loop and the earliest condensation location possibly was the cold wheat surface. It can provide theoretical basis for predicting grain-storage state.

The relationship between temperature change and micro-airflow moving will be researched further. Meanwhile how to measure and calculate the rate of the micro-airflow moving could be studied.

\section{References}

[1] R. L. Wang, et al, Grain and Oil Storage. [M] China Light Industry Press, 2012.

[2] Z. D. Wu, et al, Green Ecological Technology for Grain Storage. [M] China Science and Technology Press, 2011.

[3] Z. D. Wu, H. Y. Zhao, C. Yang, et al, "Research progress on the applications of simulation technology in grain storage ecosystem," Science and Technology of Cereals, Oils and Foods, vol. 22, no. 1, pp. 1-6, 2014.

[4] M. Izadifar, "Modeling of the packed bed drying of paddy rice using the local volume averaging approach" J. Food research international, vol. 39, no. 6, pp. 712-720, 2006.

[5] Y. Tirawanichakul, S. Prachayawarakorn, W. Varanyanond, "Simulation and grain quality for in-store drying of paddy," Journal of food Engineering, vol. 64, no. 4, pp. 405-415, 2004.

[6] Y. Jun, Z. J. Zhang, Z. D. Wu, et al, "The Moisture Change with time in Wheat Bulk under the Condition of Temperature Differences," J. The ASABE, 2016.

[7] A. Gastón, R. Abalone, R. E. Bartosik, et al, "Mathematical modelling of heat and moisture transfer of wheat stored in plastic bags (silobags)," Biosystems Engineering, vol. 104, pp. 72-85, 2009. 